\title{
Influence of a single lightning discharge on the intensity of an air electric field and acoustic emission of near-surface rocks
}

\author{
S. E. Smirnov and Y. V. Marapulets \\ Institute of Cosmophysical Research and Radio Wave Propagation (FEB RAS), Paratunka Kamchatskiy krai, Russia \\ Correspondence to: S. E. Smirnov (sergey@ikir.ru) and Y. V. Marapulets (marpl@ikir.ru)
}

Received: 2 April 2012 - Published in Solid Earth Discuss.: 7 June 2012

Revised: 27 August 2012 - Accepted: 31 August 2012 - Published: 1 October 2012

\begin{abstract}
The effect was observed as a sharp fall of the electric potential gradient from $+80 \mathrm{~V} \mathrm{~m}^{-1}$ down to $-21 \mathrm{~V} \mathrm{~m}^{-1}$. After that the field returned to its normal level according to the formula of the capacitor discharge with $17 \mathrm{~s}$ characteristic time. Simultaneously, the response of the acoustic emission of surface rocks in the range of frequencies between $6.5 \mathrm{kHz}$ and $11 \mathrm{kHz}$ was evaluated.
\end{abstract}

\section{Introduction}

In spite of a long period of investigation of lightning processes, scientific interest in these phenomena has not vanished. The currently accepted concept that the Earth's electrostatic charge is formed by planetary lightning activity requires more detailed consideration of discharge and charge transition processes in a cloud. In the paper the process of response in electric field intensity of the near-ground air and in acoustic emission on a single lightning discharge is studied.

The peculiarity of atmosphere electric state in Kamchatka is a small number of lightning strokes. Cold climate does not allow ground surface to warm up. There are no large temperature vertical gradients in the atmosphere and, consequently, the conditions for appearance of lightning clouds are very rare. According to official data from 1937 to 1982 (45 years), only 22 lightning strokes have been registered (Kondratuk, 1983). On 2 October 2008, a unique event for this region occurred. At 17:46 LT (04:46 UT) a single lightning discharge not accompanied by precipitation occurred. This discharge was visually observed by one of the authors. The reaction on this discharge was observed at "Paratunka" observatory in electric field and in acoustic emission. In the paper of Mikhailov et al. (2005), it was shown that, during precipitation, the atmospheric noise level in electric signal increases by two orders in comparison to changes in "fair weather" conditions. In this case all the physical values were measured when there was no precipitation, which allowed us to measure fields as they were. Moreover, the cloud cover on that day was not continuous but there were big cumulus clouds. Electro-impulse effect on acoustic emission activity was earlier studied on geomaterial examples (Sobolev and Ponomarev, 2003; Sobolev et al., 2000; Bogomolov et al., 2004; Zacupin et al., 2006), and on rocks under the effect of impulses emitted by magnetohydrodynamic (MHD) generator (Tarasov, 1997; Tarasov et al., 1999; Tarasov and Tarasova, 2004). In the present study, the increase of emission level in the range of $6.5-11 \mathrm{kHz}$ in sedimentary rocks under the influence of a lightning discharge was registered for the first time.

\section{Measurement technique}

Observations were carried out in Kamchatka at "Paratunka" observatory, IKIR FEB RA $S\left(\lambda=158.25^{\circ} \mathrm{E}, \varphi=52.9^{\circ} \mathrm{N}\right)$. Electric field intensity measurements were realized by "Pole2" electrostatic fluxmeter, developed in a branch of the Voeikov Main Geophysical Observatory, Scientific Research Center of Atmosphere Remote Sensing (Imynitov, 1957). "Pole-2" was installed on a test ground at the height of $3 \mathrm{~m}$ at the distance of $200 \mathrm{~m}$ from the administrative building (Fig. 1).

The area around it is cleared from trees with the radius of $12 \mathrm{~m}$. The construction of sensor installation is so that the leveled surfaces of electric field intensity at the measurement point are parallel to the Earth's surface (Fig. 2). 


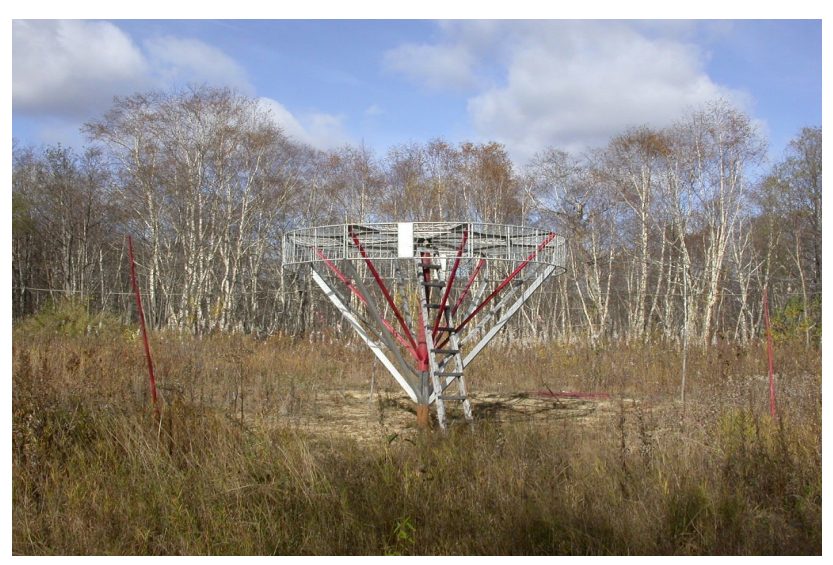

Fig. 1. "Pole-2" instrument setup at observatory test ground.

The principle of operation of "Pole-2" instrumentation is the following. Electric field intensity is transformed into electric current by rotary electrostatic generator, which operates on the basis of electrostatic induction. Electrostatic induction current of the measured field induces electric charge on a measuring plate. Modulator, the shielding plate, periodically shields the measuring plate in electric field, in the result of which the value of the induced charge periodically changes. The charge accumulating and draining from the plate generates current in the load circuit. The current amplitude is proportional to the measured electric field intensity, to the rotation frequency of modulation plate and to the area of measuring plate; the phase is determined by the electric field direction near the measuring plate surface. After digitizing by 14-bit ADC with $1 \mathrm{~s}$ sampling frequency, the signal at flux-meter output is recorded on a hard disk of a PC.

Measurement of the electric field was carried out in two channels. The first channel has a resolution of $0.25 \mathrm{~V} \mathrm{~m}^{-1}$ and the dynamic range of $\pm 200 \mathrm{~V} \mathrm{~m}^{-1}$. The second channel has a resolution of $2.5 \mathrm{~V} \mathrm{~m}^{-1}$ and the dynamic range of $\pm 2000 \mathrm{~V} \mathrm{~m}^{-1}$. For the estimations we used measurements of both channels.

Acoustic emission (AE) registration was carried out by a hydro-acoustic receiver (hydrophone) with the sensitivity of about hundreds of $\mathrm{mV} / \mathrm{Pa}$ together with embedded preamplifier; the receiver is installed in an artificial pool at the distance of 54 meters from the electric field sensor. The pit of $1 \times 1 \times 1$ was made in near-surface rocks and filled with water. Application of the hydrophone installed in a pool allowed us to register geoacoustic signal in the range of $0.1 \mathrm{~Hz}-$ $11 \mathrm{kHz}$, which is greater than ordinary seismometers. Signals from the hydrophone, after being digitized by 16-order ADC with $44100 \mathrm{~Hz}$ frequency rate, are recorded on a hard disk of a PC. Than we carry out filtration at the following frequency ranges: 0.1-10, 30-60, 70-200, 200-600, 600-2000, $2000-6500,6500-11000 \mathrm{~Hz}$ by digital filters with high quality factor, excluding interference of channels, detection and

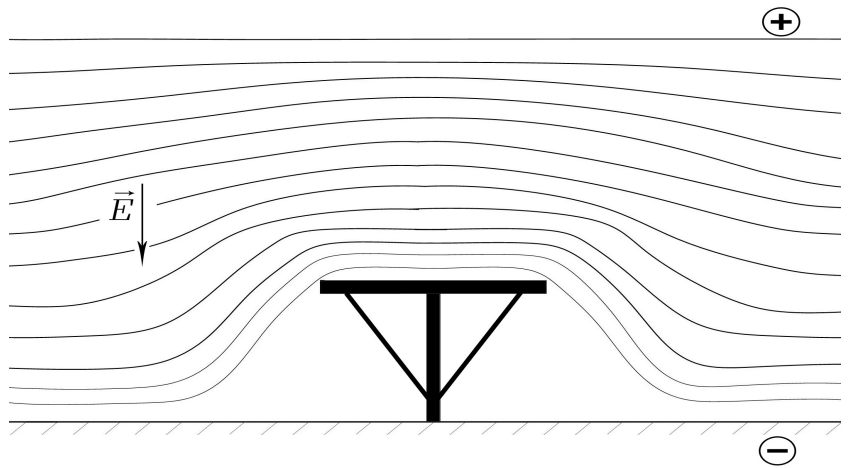

Fig. 2. Leveled surfaces of electric field intensity within the area of sensor installation

storage with $4 \mathrm{~s}$ time slot (Kuptsov, 2005). This data set is used in the following study. The analyzed value is a summary for every $4 \mathrm{~s}$ acoustic pressure $P_{S}$ at every frequency channel. The performed investigations stated that, under the influence of deformations of the order $\sim 10^{-7}$ (Dolgikh et al., 2007), an increase of emission activity is observed in the frequency range of first kilohertz which coincides with source scales of $10^{-1}-1 \mathrm{~m}$ (Kuptsov et al., 2005). This effect is the most vividly observed during strong earthquake preparation, 1-3 days before an event (Kuptsov et al., 2005).

Monitoring of meteorological parameters (air temperature and humidity, atmospheric pressure, precipitation level) is carried out by a digital meteo-station WS-2000. Magnetic field $H, D, Z$ components were measured by a fluxgate magnetometer FRG with the accuracy of $0.01 \mathrm{nT}$ and $1 \mathrm{~s}$ sampling frequency. Time synchronization was made by GPS receiver.

\section{Main results and discussion}

On 2 October 2008 in the region of the observatory, there was changeable cloudiness with big cumulus clouds. Precipitation was not observed from 14:00 to 19:00 LT (UT + 13 h). From a cloud that appeared to pass over a mountain top, a single lightning discharge occurred. There were no subsequent discharges. The lightning discharge caused a sharp fall of electric field potential gradient from $80 \mathrm{~V} \mathrm{~m}^{-1}$ to $-21 \mathrm{~V} \mathrm{~m}^{-1}$, followed by a smooth recovery up to the value of $70 \mathrm{~V} \mathrm{~m}^{-1}$ (Fig. 3). Air electroconductivity changed weakly and was about $4 \times 10^{-15} 1 /(\mathrm{Ohm} \times \mathrm{m})$. Conduction current density changed from the value of $-2 \times 10^{-13}$ to $+6 \times 10^{-13} \mathrm{~A} \mathrm{~m}^{-2}$. It was calculated with two units: one measured the conductivity of the air and the other one the gradient potential of the electric field. Conduction current density was calculated as a product of these quantities. Magnetic field change in all the tree components, which were measured with $1 \mathrm{~s}$ interval, was not registered during the lightning discharge. 

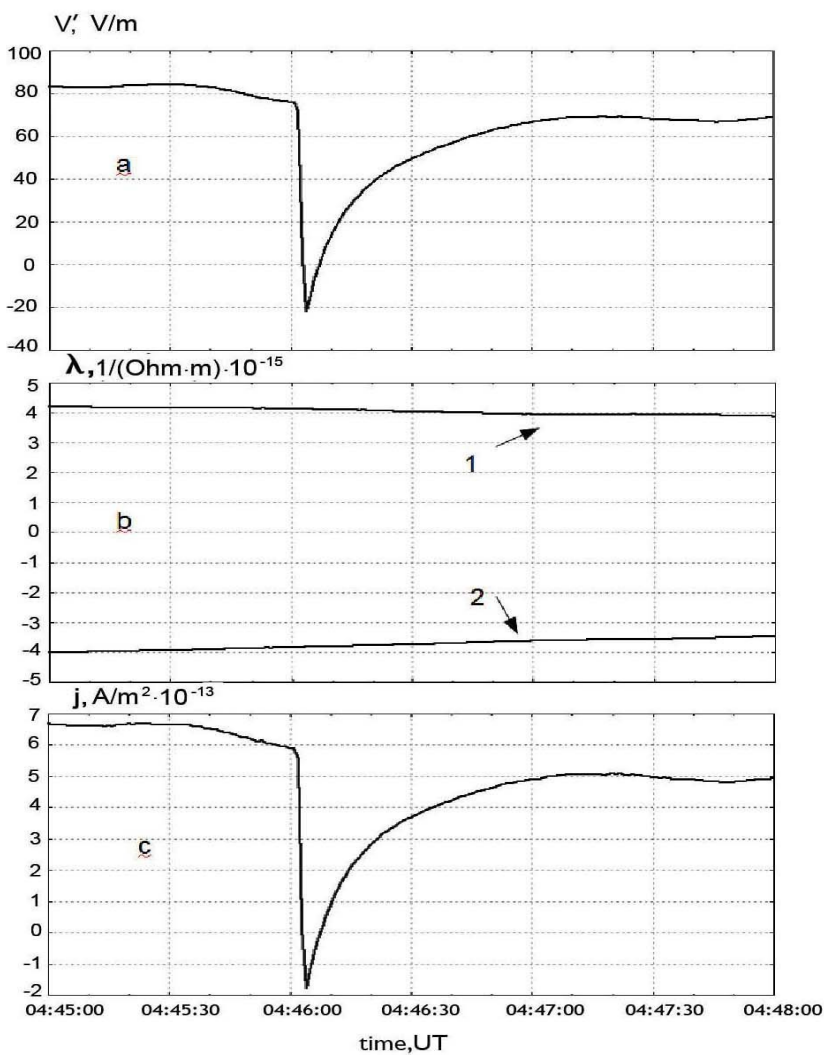

Fig. 3. Plot of field pattern during lightning discharge on 2 October 2008: (a) electric field (Ez) potential gradient in the near-ground air; (b) air electroconductivity $(\lambda)$ caused by 1 -negative ions and 2 positive ions with factor $(-1)$; (c) conduction current density (j).

During lightning, a charge of 20-30 coulombs takes place with every lightning stroke (Feynman et al., 1964). Recovery occurs according to the same law as capacitor charge recovery. Here one may observe a sudden field fall followed by exponential return to its initial value with characteristic time constant of the order of $5 \mathrm{sec}$ changing from time to time (Feynman et al., 1964). When studying ground-cloud discharges, the form of charge recovery is commonly calculated by the formula suggested by Kazemir (Chalmers, 1967):

$$
E z(t)=E z 1 \cdot \exp (-t / \tau)+E z 2 \cdot(1-\exp (-t / \tau)),
$$

where $E z(t)$ is electric field potential gradient, $E z 1$ its value right after lightning discharge, and Ez2 its value after the recovery. It determines the time of atmosphere relaxation near ground surface. According to the method of the least squares with mean squared error 0.2 , the numerical values were determined by this formula: $E z 1=-19.5 \mathrm{~V} \mathrm{~m}^{-1}$; $E z 2=69.1 \mathrm{~V} \mathrm{~m}^{-1}$.

Charge in the cloud recovered with the characteristic time of relaxation $\tau=17 \mathrm{~s}$. Moreover, $\tau$ needs to be considered within the global ground-cloud-ionosphere system, because the processes of redistribution of induced charges from a

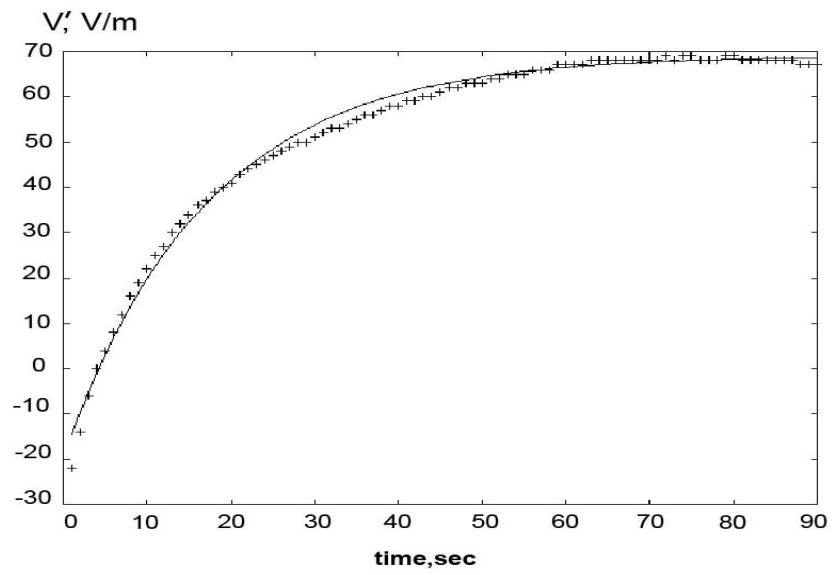

Fig. 4. Field recovery plot after lightning discharge (crosses) and approximation by the formula (2) (line).

lightning cloud on the Earth's surface by charge redistribution in the cloud itself, by the change of current groundionosphere system, are touched upon here. $E z 1$ corresponds to the surface density of charge on the ground. If we imagine cloud-ground system as a capacitor in this case, $\tau$ has physical meaning as $\tau=\mathrm{RC}$, where $R$ is resistance and $C$ capacitor capacity. Relaxation time $\tau$ is also determined by ion mobility. Usually, its average value in the regions with high lightning activity is about $7 \mathrm{~s}$ (Chalmers, 1967).

Figure 4 shows a plot of measured values and approximated curve (relaxation curve). The fact that intensity drop, contrary to the model, occurred not to zero value but to the value of $-21 \mathrm{~V} \mathrm{~m}^{-1}$ indicates a non-nil value of surface charge density.

Simultaneously with electric field, the acoustic emission response on lightning discharge was observed (Fig. 5). Signal directly from the discharge was registered in the highest frequency range of $6.5-11 \mathrm{kHz}$ (Fig. 5, ellipse 1), and the following sound wave at all the channels (Fig. 5, ellipse 2). According to the difference of arrival of these signals of $24 \mathrm{~s}$ and considering sound velocity in the air of $330 \mathrm{~m} \mathrm{~s}^{-1}$, the distance to a source was $\sim 8 \mathrm{~km}$.

Acoustic emission is elastic wave emission appearing in the process of medium inner structure reconstruction during plastic deformation. Acoustic emission phenomenon is observed in a wide range of materials, structures and processes. The most large-scale AE is associated with seismic waves, whereas the least small-scale level of acoustic emission is caused by dislocation movement in crystals. Between these two types of $\mathrm{AE}$, there is a wide range of scales of acoustic emission from laboratory tests and natural experiments to industrial control. Acoustic methods of diagnostics are widely spread in the geophysics to investigate seismic events and to simulate geomaterial examples.

Electro-impulse effect on acoustic emission had been earlier studied both in laboratory experiments on geomaterial 


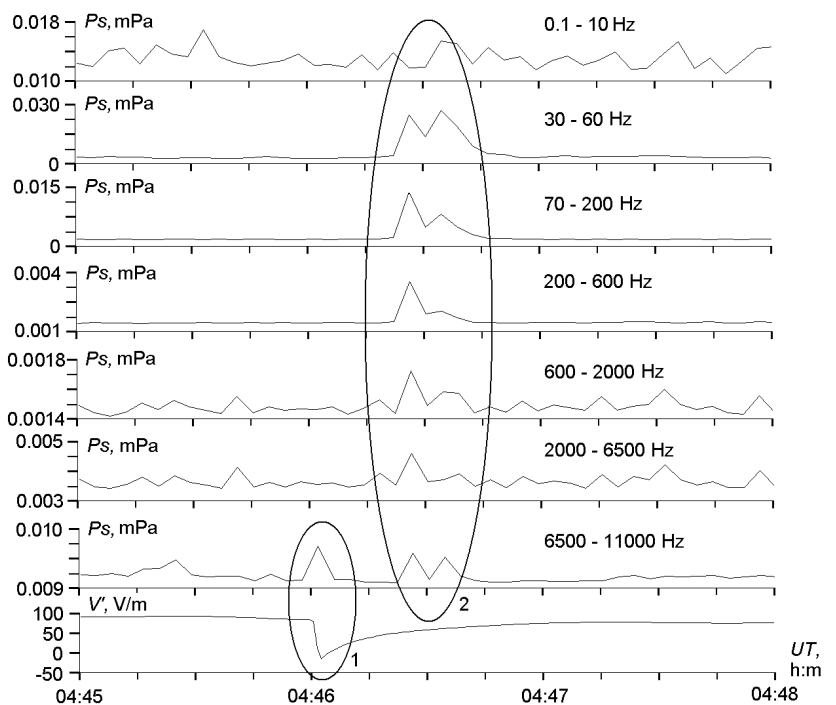

Fig. 5. Acoustic emission plots in seven frequency ranges and potential gradient of electric field intensity in the near-ground air (in the bottom) during the lightning discharge on 2 October 2008.

examples (Sobolev and Ponomarev, 2003; Sobolev et al., 2000; Bogomolov et al., 2004; Zacupin et al., 2006) and in natural conditions (Tarasov, 1997; Tarasov et al., 1999; Tarasov and Tarasova, 2004). In previous papers (Sobolev and Ponomarev, 2003; Sobolev et al., 2000), the results of experiments carried out on artificial rock samples are presented. It was shown that, during mechanic compression of examples in the range of load close to destructive one with simultaneous electro-impulse effect, increase of acoustic emission energy by the value of $\sim 10^{-3} \mathrm{~J}$ occurs. It should be noted that the effect is only observed under the influence of impulses of rectangular form. The package total energy was $\sim 10^{-3} \mathrm{~J}$, i.e. in the experiments, the value of applied electric energy was comparable to the value of released acoustic energy. Similar results were obtained on rock examples with different piezoelectric properties (Bogomolov et al., 2004; Zacupin et al., 2006). Thus, in the series of laboratory experiments, an effect of increase of acoustic emission stimulated by outer electromagnetic fields was revealed. Characteristic scales of AE sources in the case were of the order of $10^{-3}$ $10^{-2} \mathrm{~m}$.

Similar results of energy effect on rocks were obtained in natural conditions when using MHD generators at Garmsk and Bishkek test grounds (Tarasov, 1997; Tarasov et al., 1999; Tarasov and Tarasova, 2004). It was established that, after the onset of electric impulses from MHD generator, weak seismicity (with energy class $K<=6$ ) on the test grounds noticeably increased. It should be noted that the characteristic scales of sources in these experiments differed considerably form the listed above laboratory ones and were of the order of $10^{3} \mathrm{~m}$.
Acoustic emission response registered in the experiment corresponds to the results of laboratory and natural tests described above. As long as the response is observed only in the range of $6.5-11 \mathrm{kHz}$, we may suggest characteristic size of sources of $10^{-1} \mathrm{~m}$. Evaluation was carried on the basis of signal propagation in sedimentary rocks according to Brune's formula (Brune, 1970). It is one order as much as in the laboratory tests and 4 orders less than natural tests; similar effects have not been observed on such scales before. In this case the increase of acoustic emission activity under the influence of electric impulse has been registered for the first time in natural conditions during lightning discharge. Lightning discharge energy was estimated to be $10^{9}-10^{10} \mathrm{~J}$ according to the paper of Rakov and Uman (2003). Assuming that energy fall occurs according to the law of $1 / r^{2}$, we may evaluate its value at the observation point as not less than $10^{1} \mathrm{~J}$. It is 4 orders as much as the value of total electric energy when acoustic emission activity increase was observed in laboratory experiments (Sobolev and Ponomarev, 2003; Sobolev et al., 2000). In general case the law of lightning energy reduction with distance does not follow the law $1 / r^{2}$. Reduction of energy with distance from the place of discharge cloud-toground occurs according to a more complex law, which requires special instrumentation observations. We applied the law $1 / r^{2}$ for evaluation, but we did not go into the details of this process. According to our colleagues, they broke down geophysical instrumentation, which is located a few kilometers from lightning. However, the study of current distribution in the soil (telluric current) from lightning is beyond the scope of our manuscript.

\section{Conclusions}

As the result of observation of a single lightning discharge during the absence of any precipitation, the following effects were discovered:

1. There was a sharp fall of potential gradient of electric field intensity in the air at the height of $3 \mathrm{~m}$ from $80 \mathrm{~V} \mathrm{~m}^{-1}$ to $-21 \mathrm{~V} \mathrm{~m}^{-1}$. Then, the field recovered its level up to the value of $70 \mathrm{~V} \mathrm{~m}^{-1}$ with characteristic time of relaxation of $17 \mathrm{~s}$.

2. The acoustic emission response in the frequency range of $6.5-11 \mathrm{kHz}$ on natural impulse electric effect was registered for the first time.

\section{References}

Bogomolov, L. M., Il'ichev, P. V., Novikov, V. A., Okunev, V. I., Sychev, V. N., and Zakupin, A. S.: Acoustic emission response of rocks to electric power action as seismoelectric effect manifestation, Ann. Geophys., 47, 65-72, 2004, http://www.ann-geophys.net/47/65/2004/. 
Brune, J. N.: Tectonic stress and the spectra of seismic shear waves earthquakes. J. Geophys. Res., 75, 4997-5009, 1970.

Chalmers, J. A.: Atmospheric Electricity, 2nd cd., Pergamon Tarrytown, NY, 515 pp., 1967.

Dolgikh, G. I., Shvets, V. A., Chupin, V. A., Yakovenko, S. V., Kuptsov, A. V., Larionov, I. A., Marapulets, Y. V., Shevtsov, B. M., and Shirokov, O. P.: Deformation and acoustic precursors of earthquakes, Dokl. Earth Sci., 413, 281-285, 2007.

Feynman, R. P., Leighton, R. B., and Sands, M.: The Feynman Lectures on Physics: Physics of Continuous Media (AddisonWesley, London, 1964; Mir, Moscow, 1966).

Imynitov, I. M.: Instrumentation and methods to study atmosphere electricity, 483 pp., 1957.

Kondratuk, V. I.: Climate of Petropavlovsk-Kamchatskiy, Hydrometeoizdat, 150 pp., 1983.

Kuptsov, A. V.: Changes of acoustic emission character corresponding to the final stage of seismic event development, Earth Physics, 10, 825-831, 2005.

Kuptsov, A. V., Larionov, I. A., and Shevtsov, B. M.: Peculiarities of geoacoustic emission during Kamchatka earthquake preparation, Volcanol. Seismol., 5, 45-59, 2005.

Mikhailov, Y. M., Mikhailova, G. A., Kapustina, O. V., Buzevich, A. V., and Smirnov, S. E.: Peculiarities of atmospheric noises superimposed on quasi-static field variations in the near ground atmosphere of Kamchatka, Geomagn. Aeronomy, 45, 690-705, 2005.
Rakov, V. A. and Uman, M. A.: Lightning: physics and effects, Cambridge Univ. Press, USA, 2003.

Sobolev, G. A. and Ponomarev, A. V.: Physics of earthquake precursors, Nauka, 270 pp., 2003.

Sobolev, G. A., Ponomarev, A. V., Avagimov, A. A., and Zeigarnik, V. A.: Initiating acoustic emis-sion with electric action: $27-$ th General Assembly Europ. Seismological Soc (ESC), Lissabon, Portugal, 10-15, 2000.

Tarasov, N. T.: Core seismicity change under electric effect, Doklady AS, 353, 542-545, 1997.

Tarasov, N. T., Tarasova, N. V., Avagimov, A. A., and Zeigarnik, V. A.: Powerful electromagnetic5impuls effect on the seismicity of Middle Asia and Kazakhstan, Vulconol. Seismol., 4/5, 152-160, 1999.

Tarasov, N. T. and Tarasova, N. V.: Spatial-temporal structure of seismisity of the North Tien Shan and its change under the effect of high energy electromagnetic pulses manifestation, Ann. Geophys.-Italy, 47, 199-212, 2004.

Zacupin, A. S., Avagimov, A. A., and Bogomolov, L. M.: Responses of acoustic emission in geomaterials to action of electric pulses under various value of the compressive load action, Izvestiya, Physics of the Solid Earth (Fizika Zemli), 10, 43-50, 2006. 